\title{
Ciprofloxacin blocked enterohepatic circulation of diclofenac and alleviated NSAID-induced enteropathy in rats partly by inhibiting intestinal $\beta$-glucuronidase activity
}

\author{
Ze-yu ZHONG ${ }^{1}$, Bin-bin SUN ${ }^{1}$, Nan SHU ${ }^{1}$, Qiu-shi XIE ${ }^{1}$, Xian-ge TANG ${ }^{1}$, Zhao-li LING ${ }^{1}$, Fan WANG ${ }^{1}$, Kai-jing ZHAO ${ }^{1}$, Ping XU ${ }^{1}$, \\ Mian ZHANG ${ }^{1}$, Ying $\mathrm{LI}^{1}$, Yang $\mathrm{CHEN}^{1}$, Li LIU ${ }^{1}$, Lun-zhu XIA ${ }^{2, *}$, Xiao-dong LIU $^{1, *}$ \\ ${ }^{1}$ Center of Drug Metabolism and Pharmacokinetics, China Pharmaceutical University, Nanjing 210009, China; ${ }^{2}$ The First Affiliated \\ Hospital, Anhui University of Chinese Medicine, Hefei 230031, China
}

\begin{abstract}
Aim: Diclofenac is a non-steroidal anti-inflammatory drug (NSAID), which may cause serious intestinal adverse reactions (enteropathy). In this study we investigated whether co-administration of ciprofloxacin affected the pharmacokinetics of diclofenac and diclofenacinduced enteropathy in rats.

Methods: The pharmacokinetics of diclofenac was assessed in rats after receiving diclofenac (10 mg/kg, ig, or $5 \mathrm{mg} / \mathrm{kg}$, iv), with or without ciprofloxacin $(20 \mathrm{mg} / \mathrm{kg}$, ig) co-administered. After receiving 6 oral doses or 15 intravenous doses of diclofenac, the rats were sacrificed, and small intestine was removed to examine diclofenac-induced enteropathy. $\beta$-Glucuronidase activity in intestinal content, bovine liver and $E$ coli was evaluated.

Results: Following oral or intravenous administration, the pharmacokinetic profile of diclofenac displayed typical enterohepatic circulation, and co-administration of ciprofloxacin abolished the enterohepatic circulation, resulted in significant reduction in the plasma content of diclofenac. In control rats, $\beta$-glucuronidase activity in small intestinal content was region-dependent: proximal intestine $<$ distal intestine<ileal valve. Administration of ciprofloxac caused significant reduction of $\beta$-glucuronidase activity in distal small intestine, and particularly in ileal valve. Furthermore, ciprofloxacin (10-2000 $\mu \mathrm{mol} / \mathrm{L})$ dose-dependently inhibited $\beta$-glucuronidase activity in distal small intestine content or $E$ coli incubated in vitro, but did not affect that in proximal small intestine content or bovine liver incubated in vitro. After receiving 6 oral doses or 15 intravenous doses of diclofenac, typical enteropathy was developed with severe enteropathy occurred in distal small intestine. Co-administration of ciprofloxacin significantly alleviated diclofenac-induced enteropathy.

Conclusion: Co-administration of ciprofloxacin attenuated enterohepatic circulation of diclofenac and alleviated diclofenac-induced enteropathy in rats, partly via the inhibition of intestinal $\beta$-glucuronidase activity.
\end{abstract}

Keywords: non-steroidal anti-inflammatory drug; diclofenac; ciprofloxacin; pharmacokinetics; enterohepatic circulation; B-glucuronidase; enteropathy; drug-drug inetraction

Acta Pharmacologica Sinica (2016) 37: 1002-1012; doi: 10.1038/aps.2016.54; published online 16 May 2016

\section{Introduction}

Diclofenac, one of the most widely prescribed nonsteroidal anti-inflammatory drugs (NSAIDs), leads to an increased risk of serious gastrointestinal adverse events including bleeding, ulceration, and perforation of the stomach or intestines due to the inhibition of cyclo-oxygenase $\mathrm{e}^{[1]}$. The adverse drug reac-

\footnotetext{
${ }^{*}$ To whom correspondence should be addressed.

E-mail Xlunzhu@sohu.com (Lun-zhu XIA); xdliu@cpu.edu.cn (Xiao-dong LIU)

Received 2015-11-27 Accepted 2016-01-19
}

tions in the duodenum, jejunum, and ileum are collectively termed enteropathy. Obvious small intestinal damage and bleeding occur in $70 \%$ of chronic NSAID users, although most patients do not show obvious clinical symptoms ${ }^{[2]}$. Some reports have shown an association between NSAID use and significant damage to the more distal regions of the small intestine ${ }^{[3]}$.

The fluoroquinolone antimicrobial agent ciprofloxacin has a broad spectrum of activity against both gram-negative and gram-positive bacteria. Ciprofloxacin is a potent inhibitor of CYP1A2 and a weak inhibitor of CYP3A4 $4^{[4,5]}$. Some 
studies have demonstrated a drug-drug interaction when ciprofloxacin was co-administered with other drugs, including theophylline $e^{[6,7]}$, caffeine $e^{[8]}$, clozapine ${ }^{[9]}$, methadone $e^{[10]}$ and zolpidem ${ }^{[11]}$. Ciprofloxacin is commonly prescribed with analgesics for the management of infection, pain and inflammation. Co-medication with ciprofloxacin and diclofenac occurs in many clinical situations ${ }^{[12-14]}$. Several reports have shown that co-administration of ciprofloxacin significantly decreased exposure of mycophenolic acid ${ }^{[15,16]}$, partly by inhibiting $\beta$-glucuronidase ${ }^{[17]}$. Mycophenolic acid is metabolized to mycophenolic acid glucuronide in the liver and excreted via the bile. In the small intestine, mycophenolic acid glucuronide is hydrolyzed to mycophenolic acid via $\beta$-glucuronidase, leading to enterohepatic circulation. Diclofenac also displays significant characteristics of enterohepatic circulation ${ }^{[18-21]}$, in which intestinal $\beta$-glucuronidase may be involved ${ }^{[22,23]}$. It is generally accepted that enterohepatic circulation plays an important role in NSAID-induced enteropathy, which is related to enterocyte exposure to the aglycon released from tiacyl or phenol glucuronides of NSAIDs and their oxidative metabolites via $\beta$-glucuronidase ${ }^{[24]}$. All these results indicate that ciprofloxacin blocks the enterohepatic circulation of diclofenac and alleviates diclofenac-induced enteropathy.

The aim of this study was to investigate (1) whether ciprofloxacin affects the pharmacokinetics of diclofenac following oral and intravenous dosing in rats, (2) the effects of ciprofloxacin on the $\beta$-glucuronidase activity that catalyzes hydrolysis of diclofenac acyl- $\beta$-D-glucuronide (DC-AG) to diclofenac, and (3) whether inhibition of diclofenac release from DC-AG by ciprofloxacin alleviated diclofenac-induced enteropathy.

\section{Materials and methods Materials}

$\beta$-Glucuronidases from Escherichia coli (E coli) and bovine liver were purchased from Sigma Chemical Co (St Louis, MO, USA). Ciprofloxacin, diclofenac and nitroblue tetrazolium were from Dalian Meilun Biotech Co, Ltd (Dalian, China). Diclofenac acyl- $\beta$-D-glucuronide (DC-AG) was from J\&K Chemical, Ltd (Beijing, China). All the other reagents were of analytical grade and were commercially available.

\section{Animals}

Male Sprague-Dawley rats were obtained from the SIPPR/ BK Experimental Animal Co, Ltd (Shanghai, China). The animals used in this study were housed in a temperature- and humidity-controlled animal room (temperature, $22.0 \pm 21003^{\circ} \mathrm{C}$; humidity, $50 \% \pm 5 \%$ ) with a 12-h light/dark cycle and had free access to water and standard chow. Animal experiments were carried out according to the institutional guidelines for the care and the use of laboratory animals and approved by the Animal Ethics Committee of China Pharmaceutical University.

Effects of ciprofloxacin on diclofenac pharmacokinetics and diclofenac-induced enteropathy following oral administration

The pharmacokinetics of diclofenac and diclofenac-induced enteropathy following the oral administration of diclofenac were investigated. Thirty-two rats weighing $273 \pm 11 \mathrm{~g}$ (7 weeks old) were randomly divided into four groups of eight rats each: diclofenac (DC), diclofenac+ciprofloxacin $(\mathrm{DC}+\mathrm{CP})$, ciprofloxacin $(\mathrm{CP})$ and controls $(\mathrm{CON})$. The $\mathrm{DC}, \mathrm{DC}+\mathrm{CP}$ and $\mathrm{CP}$ rats received oral diclofenac $(10 \mathrm{mg} / \mathrm{kg})$ alone, diclofenac $(10 \mathrm{mg} / \mathrm{kg})$ co-administered with ciprofloxacin $(20 \mathrm{mg} / \mathrm{kg})$ and ciprofloxacin $(20 \mathrm{mg} / \mathrm{kg})$ alone daily for $6 \mathrm{~d}$, respectively. The CON rats received only an equivalent volume of physiological saline. The doses of ciprofloxacin and diclofenac were as in previous reports ${ }^{[19,25-28]}$ and corresponded to clinical use.

The pharmacokinetics of diclofenac were determined on d 1 and 5 following dosing. Briefly, blood samples (approximately $0.15 \mathrm{~mL}$ ) were collected via the oculi chorioideae vein under light ether anesthesia at 5, 15, 30, 60, 120, 180, 300, 420, 540 and 720 min after the oral administration of diclofenac. After 3 or 4 samples were taken, an appropriate amount of normal saline was injected via the tail vein to compensate for blood loss. Plasma samples were obtained by centrifugation and stored at $-80^{\circ} \mathrm{C}$ until analysis.

On $\mathrm{d}$ 6, $2 \mathrm{~h}$ after the last dose of diclofenac, the rats were sacrificed under ether anesthesia. The small intestine (from the gastroduodenal junction to the ileocecal junction) was quickly removed to assess enteropathy. The intestinal contents of the $\mathrm{CP}$ rats and the $\mathrm{CON}$ rats were also collected, to assess the hydrolysis of DC-AG.

\section{Effects of ciprofloxacin on the pharmacokinetics of diclofenac} and diclofenac-induced enteropathy following intravenous administration

The pharmacokinetics of diclofenac and diclofenac-induced enteropathy following intravenous administration of diclofenac were also investigated. Twenty-four rats weighing $281 \pm 14$ $\mathrm{g}$ (7 weeks old) were randomly divided into three groups of eight rats each: diclofenac (DC), diclofenac+ciprofloxacin $(\mathrm{DC}+\mathrm{CP})$, and controls $(\mathrm{CON})$. $\mathrm{DC}$ and $\mathrm{DC}+\mathrm{CP}$ rats intravenously received diclofenac $(5 \mathrm{mg} / \mathrm{kg})$ alone and diclofenac coadministered with oral ciprofloxacin $(20 \mathrm{mg} / \mathrm{kg})$ daily for 15 $\mathrm{d}$, respectively. Diclofenac was intravenously administered to rats via the tail vein $1 \mathrm{~min}$ after oral ciprofloxacin was given. The control rats received only physiological saline. On d 1, blood samples (approximately $0.15 \mathrm{~mL}$ ) were collected from the rats under light ether anesthesia via the oculi chorioideae vein at 5, 15, 30, 45, 60, 90, 120, 180, 240, 360 and $480 \mathrm{~min}$ following dosing with diclofenac to evaluate the pharmacokinetics of diclofenac.

On $\mathrm{d} 15$, the experimental rats, which had been fasted overnight, were sacrificed under ether anesthesia $2 \mathrm{~h}$ following the last dose of diclofenac to assess enteropathy and measure the concentration of diclofenac and DC-AG in the intestinal contents. Briefly, the entire small intestine was removed and divided into four quartiles of equal length, and the intestine segments were gently rinsed with $2 \mathrm{~mL}$ of cold PBS, followed by another $3 \mathrm{~mL}$ of cold PBS. The two eluates (total volume $5 \mathrm{~mL}$ ) were combined, and the concentrations of diclofenac and DC-AG in the mixed eluates were measured using HPLC. Then, each intestine segment was assessed for diclofenac- 
induced enteropathy.

\section{Effects of ciprofloxacin on diclofenac absorption}

The effects of ciprofloxacin on diclofenac absorption were evaluated by in situ single-pass perfusion as described previously $^{[29]}$. In brief, rats were fasted overnight and then anesthetized with pentobarbital $(60 \mathrm{mg} / \mathrm{kg}$, ip). Next, two cannulas (input and output) were inserted at either end of the isolated jejunum $(10 \mathrm{~cm})$. The isolated intestine segment was flushed with a $0.9 \%$ saline solution $\left(37^{\circ} \mathrm{C}\right.$ ) at $0.2 \mathrm{~mL} / \mathrm{min}$ for $10 \mathrm{~min}$, followed by Krebs-Henseleit buffer containing diclofenac (10 $\mu \mathrm{mol} / \mathrm{L})$ with or without ciprofloxacin $(200 \mu \mathrm{mol} / \mathrm{L})$ for 15 min until a steady state was reached. Consecutive effluent samples were collected at 15-min intervals through the distal cannula for $120 \mathrm{~min}$. The rats were sacrificed at the end of the perfusion, and the perfused intestinal segments were removed in order to measure the areas of absorption. The apparent effective permeability $\left(\mathrm{P}_{\text {eff }}, \mathrm{cm} / \mathrm{min}\right)$ was calculated according to the following equation: $P_{\text {eff }}=-Q \cdot \ln \left(C_{\text {out }} / C_{\text {in }}\right) / A$, where $C_{\text {out }}$ $(\mu \mathrm{g} / \mathrm{mL})$ and $\mathrm{C}_{\mathrm{in}}$ are the diclofenac concentrations in the output and input solutions, respectively. $\mathrm{A}\left(\mathrm{cm}^{2}\right)$ represents the area of the perfused intestinal segment, and $Q(\mathrm{~mL} / \mathrm{min})$ is the flow rate. The water flux was corrected using a gravimetric method $^{[30]}$

\section{Effects of ciprofloxacin on biliary excretion of diclofenac}

Twelve rats weighing 295 $\pm 14 \mathrm{~g}$ were divided into DC and $\mathrm{DC}+\mathrm{CP}$ groups. The rats were anesthetized with diethyl ether, and a PE-10 tube was inserted into the common bile duct. After bile flow was confirmed, the DC+CP rats and DC rats intravenously received diclofenac $(5 \mathrm{mg} / \mathrm{kg})$ via the tail vein following iv adminsitration of ciprofloxacin $(5 \mathrm{mg} / \mathrm{kg})$ or physiological saline, respectively. Bile was collected into containers before dosing and at intervals of 0 to $20 \mathrm{~min}, 20$ to $40 \mathrm{~min}, 40$ to $60 \mathrm{~min}, 60$ to $90 \mathrm{~min}, 90$ to $120 \mathrm{~min}$ and 120 to 180 min after the diclofenac dose for measurement of the diclofenac and DC-AG concentrations.

\section{Assay of $\beta$-glucuronidase activity in intestinal contents from $\mathrm{CP}$ and $\mathrm{CON}$ rats}

To measure $\beta$-glucuronidase activity in intestinal contents, the entire small intestine of the $\mathrm{CP}$ rats and $\mathrm{CON}$ rats was quickly removed and divided into halves. The segment next to the stomach and the segment before the cecum were defined as the proximal small intestine and distal small intestine, respectively. The contents of the proximal small intestine, the distal small intestine and the ileal valve were collected and mixed with PBS ( $\mathrm{pH} 5.5)$ in an ice-water bath, and an appropriate dilution was made based on a preliminary experiment. The intestinal $\beta$-glucuronidase activity, defined as diclofenac formation from DC-AG, was measured according to a previously described method ${ }^{[22,31]}$ with minor modifications. Briefly, the reaction was initiated by the addition of $100 \mu \mathrm{L}$ of intestinal content solution pre-incubated at $37^{\circ} \mathrm{C}$ in a reaction tube containing DC-AG (final level: $10 \mu \mathrm{mol} / \mathrm{L}$ ). Following a 5-min incubation, the reaction was quenched by the addition of $200 \mu \mathrm{L}$ acetonitrile containing $5 \mathrm{~mol} / \mathrm{L}$ phosphoric acid and $2 \mu \mathrm{g} / \mathrm{mL}$ chloroxazone as an internal standard. Diclofenac formation was measured by HPLC. The protein concentration of the intestinal contents was determined by a bicinchoninic protein assay (BCA) kit (Nanjing Jiancheng Bioengineering Institute, Nanjing, China). The $\beta$-glucuronidase activity was normalized by protein concentration in the intestinal contents and expressed as the formation of diclofenac per $\mathrm{mg}$ protein.

Effects of ciprofloxacin on activities of $\beta$-glucuronidase in the intestinal content and the purified $\beta$-glucuronidase from bovine liver or $E$ coli

The effects of ciprofloxacin on $\beta$-glucuronidase activity in the small intestinal contents of normal rats and purified $\beta$-glucuronidase were investigated. D-saccharic acid 1,4-lactone monohydrate served as a positive inhibitor. Briefly, the reaction was initiated by adding $20 \mu \mathrm{L}$ ciprofloxacin and $80 \mu \mathrm{L}$ intestinal contents or enzyme solution preincubated at $37^{\circ} \mathrm{C}$ to a tube containing DC-AG (final levels: $10 \mu \mathrm{mol} / \mathrm{L})$. Following a 5-min incubation, the reaction was stopped by adding $200 \mu \mathrm{L}$ acetonitrile solution containing $5 \mathrm{~mol} / \mathrm{L}$ phosphoric acid and $2 \mu \mathrm{g} / \mathrm{mL}$ chloroxazone as an internal standard. The $\beta$-glucuronidase activity was expressed as the formation of diclofenac per $\mathrm{mg}$ protein or in units.

\section{Assessment of diclofenac-induced enteropathy}

Diclofenac-induced enteropathy was assessed as previously described $^{[22]}$. The excised small intestine was divided into four segments of approximately equal length and opened longitudinally along the antimesenteric side. The segment next to the stomach and the segment before the cecum were defined as the first quartile and the fourth quartile, respectively. The segments were rinsed with ice-cold phosphate buffered saline, followed by incubation for $15 \mathrm{~min}$ in a $1 \mathrm{mmol} / \mathrm{L}$ nitroblue tetrazolium (NBT) solution containing $16 \mathrm{mmol} / \mathrm{L} \mathrm{HEPES,} 125$ $\mathrm{mmol} / \mathrm{L} \mathrm{NaCl}, 3.5 \mathrm{mmol} / \mathrm{L} \mathrm{KCl}$, and $10 \mathrm{mmol} / \mathrm{L}$ glucose. The stained tissues were fixed in $10 \%$ buffered formalin for $24 \mathrm{~h}$ and transferred to $70 \%$ ethanol. The luminal side of the intestine was photographed with a Tanon 5200 Multi Chemiluminescent System. The numbers and area of the lesions were observed and quantified with a Gel Imaging System (Tanon technology Co, Ltd, Shanghai, China) by an observer without knowledge of the treatment. Representative parts of the formalin-fixed tissues were embedded in paraffin, and 5- $\mu \mathrm{m}$ sections were stained with hematoxylin/eosin for histopathological analysis and examination by light microscopy $(\times 40)$.

\section{Drug analysis}

Concentrations of diclofenac in rat plasma and the incubation system were determined by HPLC with an ultraviolet detector, as previously described ${ }^{[32]}$ with minor modifications. Briefly, for plasma samples, $50 \mu \mathrm{L}$ plasma was spiked with 10 $\mu \mathrm{L}$ of $2 \mu \mathrm{g} / \mathrm{mL}$ chloroxazone as an internal standard and 100 $\mu \mathrm{L}$ acetonitrile. For the incubation samples, the reaction was 
stopped by adding $200 \mu \mathrm{L}$ of an acetonitrile solution containing $5 \mathrm{~mol} / \mathrm{L}$ phosphoric acid and $2 \mu \mathrm{g} / \mathrm{mL}$ chloroxazone as an internal standard. For the simultaneous analysis of DC-AG and diclofenac, $20 \mu \mathrm{L}$ bile or $50 \mu \mathrm{L}$ an intestinal eluate sample were mixed with $200 \mu \mathrm{L}$ of acetonitrile solution containing 5 mol/L phosphoric acid and $2 \mu \mathrm{g} / \mathrm{mL}$ chloroxazone immediately after the samples were collected. Then, the samples were vortexed. After centrifugation at 18000 rounds per minute for $10 \mathrm{~min}, 20 \mu \mathrm{L}$ of the supernatant was injected into an HPLCUV system, with the wavelength set at $276 \mathrm{~nm}$. Chromatography was performed on a Waters C18 column $(150 \mathrm{~mm} \times 4.6$ $\mathrm{mm}, 5 \mu \mathrm{m}$, Waters, USA). The mobile phase consisted of $0.015 \%$ phosphoric acid and acetonitrile $(45: 55, v / v)$, with a flow rate of $1.0 \mathrm{~mL} / \mathrm{min}$. The methods for measuring diclofenac were validated over a concentration range of $0.25-32.00$ $\mu \mathrm{g} / \mathrm{mL}$ in plasma, $0.25-16.00 \mu \mathrm{g} / \mathrm{mL}$ in intestinal elute, 1.00 $32.00 \mu \mathrm{g} / \mathrm{mL}$ in bile and $0.125-8.00 \mu \mathrm{g} / \mathrm{mL}$ in the incubation system. The LLOQs of diclofenac in these biological samples were $0.25,0.25,1.00$ and $0.125 \mu \mathrm{g} / \mathrm{mL}$, respectively. The methods for measuring DC-AG were also validated over a concentration range of $0.3125-20.00 \mu \mathrm{g} / \mathrm{mL}$ in intestinal elute and $10.00-200.00 \mu \mathrm{g} / \mathrm{mL}$ in bile, and the LLOQs were 0.3125 and $20.00 \mu \mathrm{g} / \mathrm{mL}$, respectively. The relative standard deviations of the intra-day precision values (RSD) for the three concentrations of analytes were less than $10 \%$, and their accuracies ranged from $85 \%$ to $115 \%$.

\section{Data and statistical analysis}

The pharmacokinetic parameters were estimated using a noncompartmental analysis (Pheonix Winnonlin 6.3, Pharsight, St Louis, MO, USA). All data were expressed as the mean \pm SD. If the data fit a normal distribution, a standard analysis of variance was used. The significant difference between two groups was determined by Student's $t$-test. If the data were not normally distributed, a Mann-Whitney U test was used for a comparison between two groups.

\section{Results}

Effects of co-administration of ciprofloxacin on the pharmacokinetics of diclofenac in rats

The plasma concentrations of diclofenac were measured following the oral administration of diclofenac $(10 \mathrm{mg} / \mathrm{kg})$ to rats (Figure 1A), and the corresponding pharmacokinetic parameters were estimated (Table 1). Consistent with previous reports ${ }^{[18,26]}$, a typical double-peak was observed in the diclofenac profile following an oral dose of diclofenac. The concentration of the first peak $\left(C_{\max 1}\right)$ and the concentration of the secondary peak $\left(C_{\max 2}\right)$ were measured at approximately 10 and $210 \mathrm{~min}$, respectively. Co-administration of ciprofloxacin decreased the $C_{\max 2}$ of diclofenac $(1.24 \pm 0.50 \mathrm{mg} / \mathrm{L}$ in coadministered ciprofloxacin vs $2.06 \pm 1.16 \mathrm{mg} / \mathrm{L}$ in diclofenac alone, $P=0.09$ ), accompanied by significant prolongation of $T_{\max 2}(390.0 \pm 124.2 \mathrm{~min}$ in co-administered ciprofloxacin $v s$ $210.0 \pm 147.0 \mathrm{~min}$ diclofenac alone, $P=0.02$ ). However, the concentration of the first peak of diclofenac was less affected by the co-administration of ciprofloxacin. The decrease in the plasma concentration of diclofenac by co-administration of ciprofloxacin primarily occurred within $300 \mathrm{~min}$, therefore the early exposure of diclofenac $\left(\mathrm{AUC}_{0-300 \mathrm{~min}}\right)$ was also calculated. The results showed that the co-administration of ciprofloxacin significantly decreased the $\mathrm{AUC}_{0-300 \text { min }}$ of diclofenac, to $61 \%$ of the value in control rats. Similar alterations in the pharmacokinetic parameters were observed following the 5 th dose of diclofenac, but the data showed no significant differences between the two groups due to large individual variability (Figure 1B, Table 1).

The pharmacokinetics of diclofenac following the intravenous administration of diclofenac with and without ciprofloxacin was determined, and typical enterohepatic circulation of diclofenac also occurred (Figure 1C). All of the DC rats displayed obvious secondary peaks in their iv pharmacokinetics profiles, while DC+CP rats did not show clear secondary peaks. Co-administration of ciprofloxacin remarkably attenu-

Table 1. Effects of orally co-administrated ciprofloxacin (CP, $20 \mathrm{mg} / \mathrm{kg}$ ) on pharmacokinetic parameters of diclofenac after oral (DC, $10 \mathrm{mg} / \mathrm{kg})$ or intravenous ( $5 \mathrm{mg} / \mathrm{kg}$ ) administration to rats. Data represent the mean $\pm \mathrm{SD}$ (median) of 8 rats. ${ }^{*} P<0.05,{ }^{* *} P<0.01$ vs DC rats.

\begin{tabular}{|c|c|c|c|c|}
\hline \multirow[t]{2}{*}{ Parameters } & \multicolumn{2}{|c|}{ Single dose } & \multicolumn{2}{|c|}{ Multidoses } \\
\hline & DC & $\mathrm{DC}+\mathrm{CP}$ & DC & $\mathrm{DC}+\mathrm{CP}$ \\
\hline \multicolumn{5}{|l|}{ Oral pharmacokinetics } \\
\hline$T_{\max 1}(\min )$ & $11.3 \pm 5.2(15.0)$ & $12.9 \pm 9.1(15.0)$ & $19.4 \pm 9.4(15.0)$ & $12.5 \pm 4.6(15.0)$ \\
\hline$C_{\max 1}(\mathrm{mg} / \mathrm{L})$ & $3.26 \pm 1.26(3.59)$ & $3.01 \pm 0.87(3.21)$ & $2.93 \pm 1.18(2.90)$ & $2.59 \pm 1.93(1.74)$ \\
\hline$T_{\max 2}(\min )$ & $210.0 \pm 147.0(150.0)$ & $390.0 \pm 124.2(420.0)^{*}$ & $292.5 \pm 164.9(240.0)$ & $300.0 \pm 111.1(300.0)$ \\
\hline$C_{\max 2}(\mathrm{mg} / \mathrm{L})$ & $2.06 \pm 1.16(1.49)$ & $1.24 \pm 0.50(1.26)$ & $2.55 \pm 1.93(1.72)$ & $1.38 \pm 0.47(1.35)$ \\
\hline $\mathrm{AUC}_{0-300 \min }\left(\mathrm{mg} \cdot \min \cdot \mathrm{L}^{-1}\right)$ & $406.45 \pm 180.08(407.88)$ & $248.76 \pm 82.76(250.87)^{*}$ & $405.14 \pm 176.14$ (338.95) & $268.56 \pm 118.68(299.77)$ \\
\hline$A \cup C_{0-720 \min }\left(\mathrm{mg} \cdot \min \cdot L^{-1}\right)$ & $602.05 \pm 174.04$ (610.98) & $507.37 \pm 88.67(529.32)$ & $641.26 \pm 145.65(687.06)$ & $538.76 \pm 92.90(570.27)$ \\
\hline \multicolumn{5}{|c|}{ Intravenous pharmacokinetics } \\
\hline $\mathrm{AUC}_{0-480 \min }\left(\mathrm{mg} \cdot \min \cdot \mathrm{L}^{-1}\right)$ & $638.20 \pm 71.38(647.67)$ & $494.75 \pm 65.81(510.50)^{*}$ & & \\
\hline $\mathrm{CL}\left(\mathrm{L} \cdot \mathrm{min}^{-1} \cdot \mathrm{kg}^{-1}\right)$ & $0.0072 \pm 0.0009(0.0071)$ & $0.0082 \pm 0.0017(0.0079)$ & & \\
\hline$T_{\max 2}(\min )$ & $175.0 \pm 61.2(180.0)$ & $377.1 \pm 108.0(360.0)^{* *}$ & & \\
\hline$C_{\max 2}(\mathrm{mg} / \mathrm{L})$ & $1.47 \pm 0.52(1.29)$ & $0.59 \pm 0.21(0.58)^{* *}$ & & \\
\hline
\end{tabular}


A

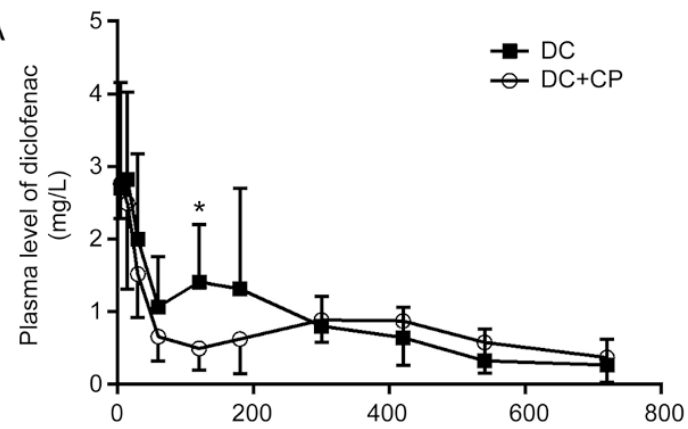

B

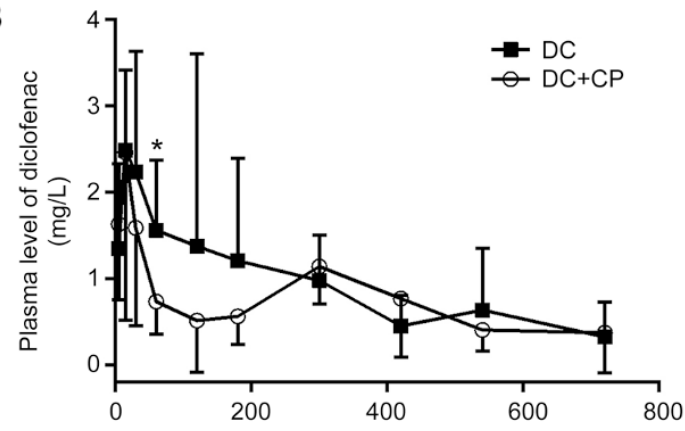

C

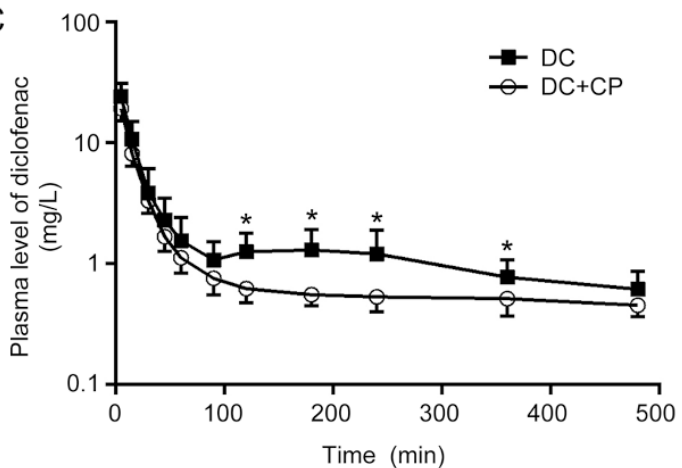

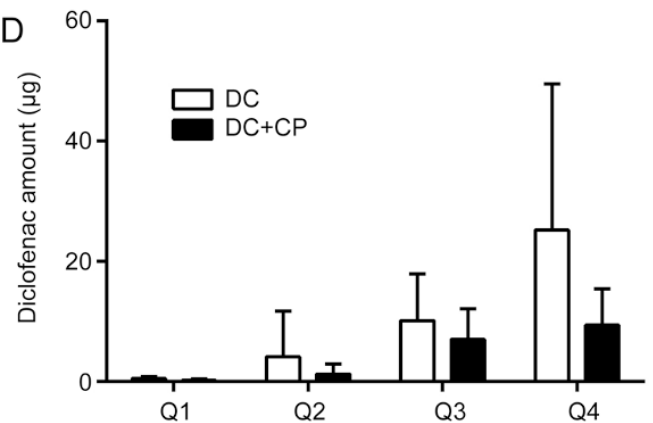
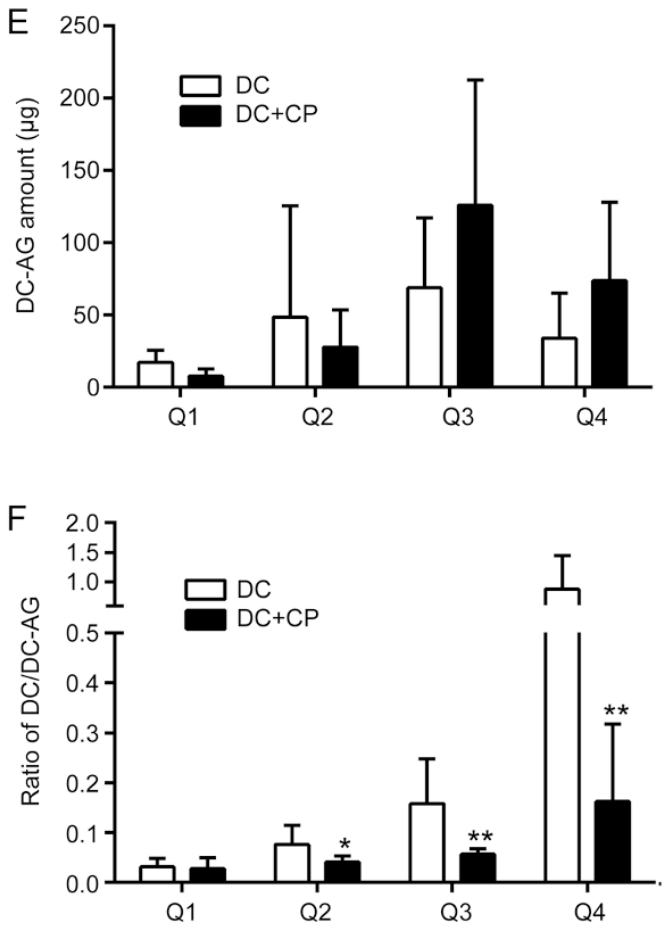

Figure 1. Plasma concentration-time profiles of diclofenac (DC) following (A) a single oral dose of DC (10 mg/kg), (B) 5 oral doses of DC (10 mg.kg-1 $\left.\mathrm{d}^{-1}\right)$ and $(C)$ an intravenous single dose of DC $(5 \mathrm{mg} / \mathrm{kg}$ ) with or without co-administration of oral ciprofloxacin (CP, $20 \mathrm{mg} / \mathrm{kg})$. The amount of DC (D), diclofenac acyl glucuronide (DC-AG, E) and their ratios (F) at $2 \mathrm{~h}$ following the last 15 intravenous doses of DC. The quartile numbers (Q1-Q4) were assigned to four small intestinal segments of equal length from the gastroduodenal junction to the ileocecal junction. The data are expressed as the mean \pm SD of 8 rats. ${ }^{*} P<0.05,{ }^{* *} P<0.01$ vs DC rats.

ated the enterohepatic circulation of diclofenac, leading to a significant decrease in the AUC of diclofenac $(494.75 \pm 65.81$ $\mathrm{mg} \cdot \mathrm{min} / \mathrm{L}$ when co-administered ciprofloxacin vs $638.20 \pm 71.38$ $\mathrm{mg} \cdot \mathrm{min} / \mathrm{L}$ diclofenac alone, $P<0.01)$, accompanied by a significant decrease in the $C_{\max 2}$ of diclofenac $(0.59 \pm 0.21 \mathrm{mg} / \mathrm{L}$ in co-administered ciprofloxacin $v s 1.47 \pm 0.52 \mathrm{mg} / \mathrm{L}$ in diclofenac alone, $P<0.01)$ and a longer $T_{\max 2}(377.1 \pm 108.0 \mathrm{~min}$ in co-administered ciprofloxacin vs $175.0 \pm 61.2 \mathrm{~min}$ diclofenac alone, $P<0.01$ ). The diclofenac and DC-AG levels in the small intestine contents were also measured at $2 \mathrm{~h}$ after the last intravenous dose of diclofenac (Figure 1D and 1E). The results showed that the diclofenac levels gradually increased from quartile 1 to quartile 4. High levels of DC-AG were found in quartiles 2 and 3 of the small intestine. Co-administration of ciprofloxacin showed a trend toward decreased levels of diclofenac and increased levels of DC-AG in the content of the small intestine, leading to a significant decrease in the diclofenac to DC-AG ratio (Figure 1F).

Effects of ciprofloxacin on the absorption and biliary excretion of diclofenac

An in situ single-pass intestinal perfusion was performed to investigate the effect of ciprofloxacin on the absorption of diclofenac (Figure 2A and 2B). The results showed that co-administration of ciprofloxacin did not affect diclofenac absorption. 
A
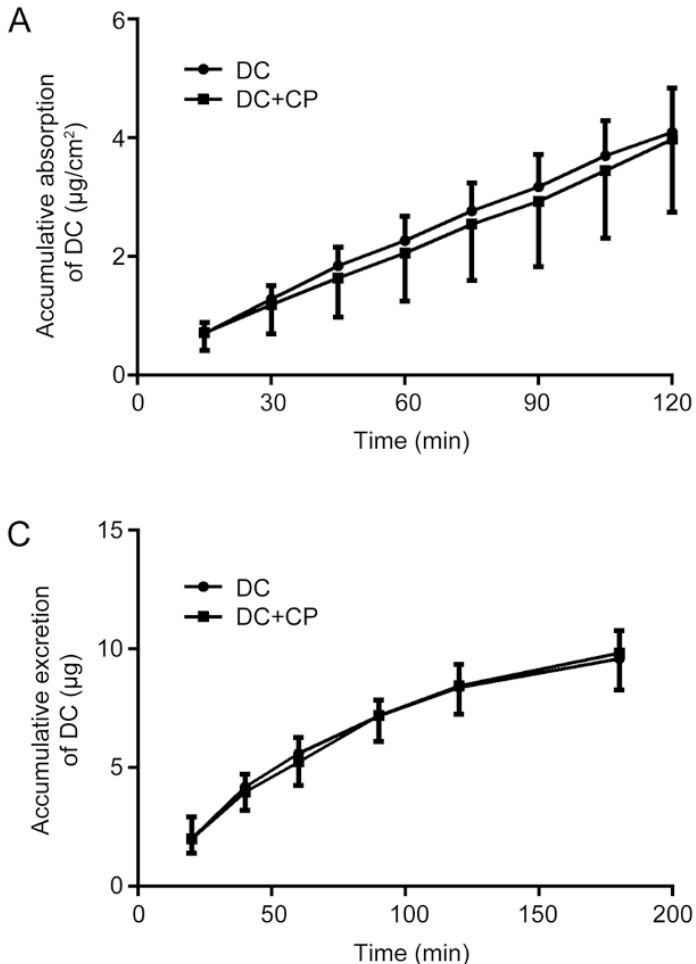
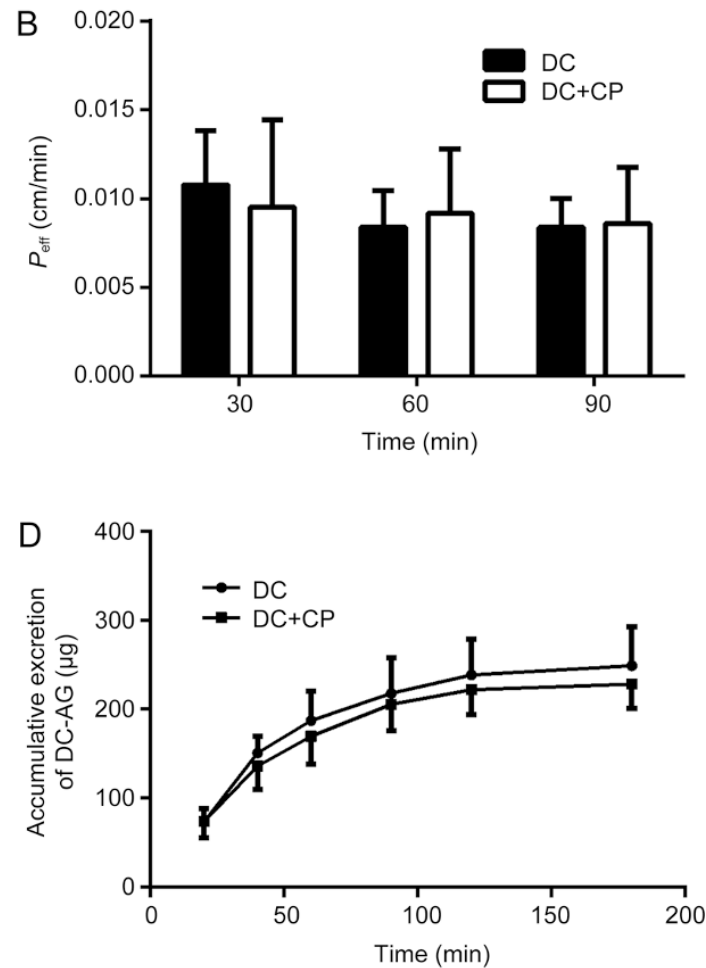

Figure 2. The effects of ciprofloxacin (CP) on the absorption of diclofenac (DC) in the jejunum of rats. The accumulative DC absorption (A) and the corresponding $P_{\text {eff }}(B)$ were measured using an in situ single-pass intestinal perfusion. The data are expressed as mean \pm SD of 5 rats. The excretion of DC (C) and DC-AG (D) via the bile following intravenous DC (5 mg/ $/ \mathrm{kg})$ alone or intravenous co-administered ciprofloxacin (CP, $5 \mathrm{mg} / \mathrm{kg})$ in rats. The data are expressed as the mean \pm SD of 6 rats.

Biliary excretion of diclofenac was determined to investigate whether ciprofloxacin impaired the enterohepatic recycling of diclofenac by inhibiting the biliary excretion of diclofenac and DC-AG (Figure 2C and 2D). The results showed that trace amounts of diclofenac were excreted in the bile, while a large amount of DC-AG was detected in the bile, which accounted for approximately $19 \%$ of the iv dose. Co-administration of ciprofloxacin affected neither the biliary excretion of diclofenac nor DC-AG.

$\beta$-Glucuronidase activity in the small intestinal content from rats treated with ciprofloxacin

$\beta$-Glucuronidase activity, defined as the formation of diclofenac from DC-AG in the proximal small intestine, distal small intestine and the ileocecal valve was measured in $\mathrm{CON}$ rats and $\mathrm{CP}$-treated rats (Figure 3A). The results showed that diclofenac formation from DC-AG in the intestinal contents was region-dependent, and the highest $\beta$-glucuronidase activity was found in the ileal valve of CON rats. The order of diclofenac formation rate in the small intestinal segments of the $\mathrm{CON}$ rats was proximal intestine $<$ distal intestine $<$ ileal valve. The effects of ciprofloxacin on the diclofenac formation in the intestinal contents were also region-dependent. Diclofenac formation in both the distal small intestine and the ileal valve of rats treated with ciprofloxacin was significantly lower than in the CON rats, while the extent of decrease in the distal small intestine of rats treated with ciprofloxacin was less than that in the ileal valve. The diclofenac formation in the proximal small intestine was not affected by pre-treatment with ciprofloxacin.

Effects of ciprofloxacin on $\beta$-glucuronidase activity in the small intestinal contents of normal rats and purified $\beta$-glucuronidase from bovine liver and $E$ coli

The effects of the in vitro incubation of ciprofloxacin on $\beta$-glucuronidase activity in both the proximal small intestine (Figure $3 \mathrm{~B}$ ) and the distal small intestine (Figure 3C) of normal rats were assessed using diclofenac formation. The results showed that the inhibition by ciprofloxacin of diclofenac formation was also region-dependent. Ciprofloxacin concentration-dependently inhibited diclofenac formation in the distal intestinal content with an $\mathrm{IC}_{50}$ of $320.65 \mu \mathrm{mol} / \mathrm{L}$. However, diclofenac formation in the proximal small intestinal contents was slightly inhibited by ciprofloxacin although D-Saccharic acid 1,4-lactone monohydrate still showed strong inhibition.

The effects of ciprofloxacin on $\beta$-glucuronidase activity were further characterized using purified $\beta$-glucuronidases from bovine liver and $E$ coli, representing a mammalian ortho$\log$ and a microfloral secretion, respectively. Ciprofloxacin strongly inhibited the activity of $\beta$-glucuronidase from $E$ coli (Figure 3E), with an $\mathrm{IC}_{50}$ of $27.06 \mu \mathrm{mol} / \mathrm{L}$. However, the activ- 

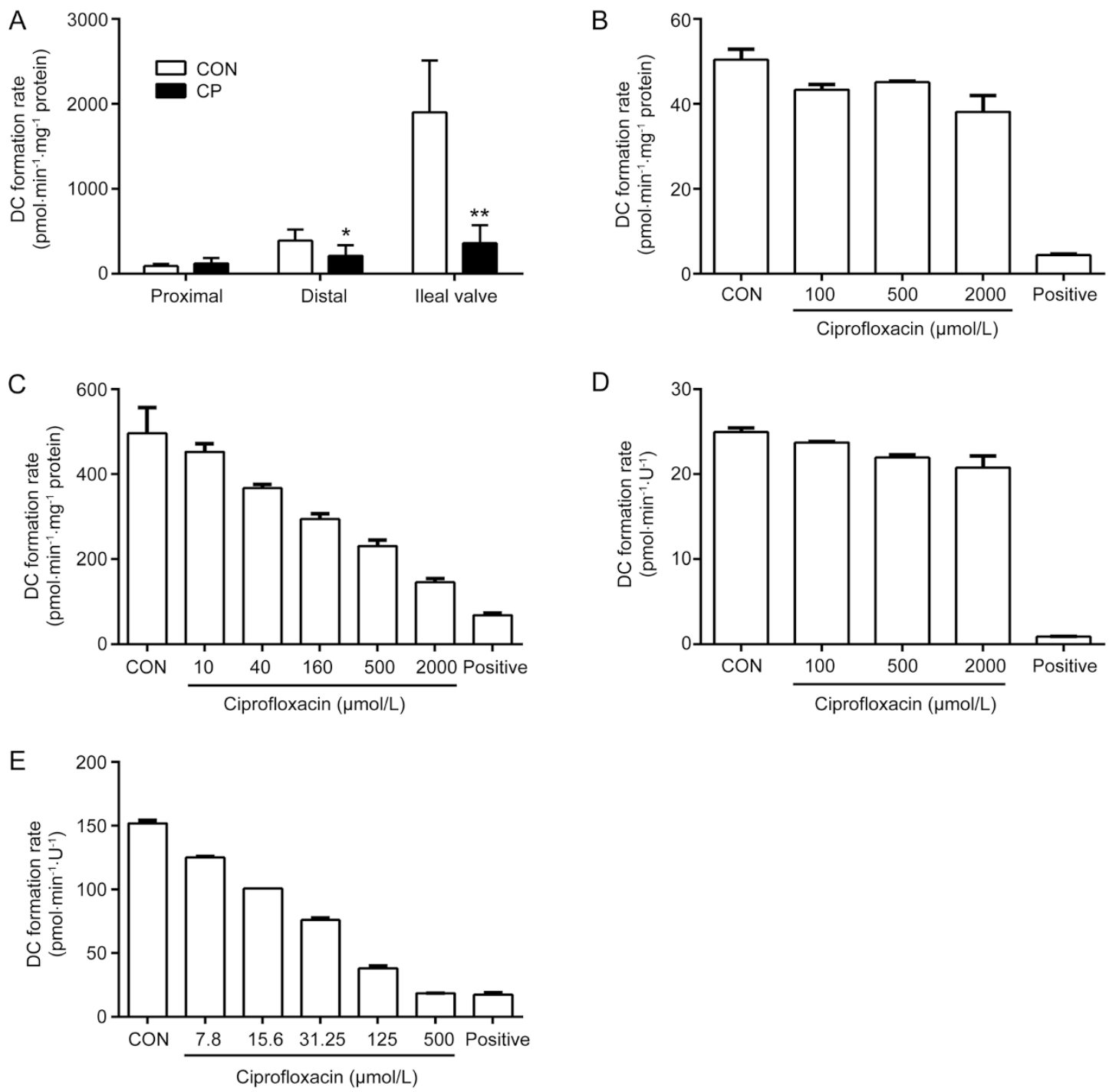

Figure 3. Diclofenac (DC) formation from diclofenac acyl glucuronide in the intestinal contents of CON rats and CP-treated rats (A). The data are expressed as the mean \pm SD $(n=8)$. ${ }^{*} P<0.05,{ }^{* *} P<0.01$ vs CON rats. The effects of the in vitro incubation of ciprofloxacin on $\beta$-glucuronidase activity defined as the rate of diclofenac formation in the proximal small intestinal contents (B), the distal small intestinal contents (C) from normal rats and purified $\beta$-glucuronidase from bovine liver (D) and $E$ coli $(E)$. All incubations were performed in triplicate.

ity of $\beta$-glucuronidase from bovine liver was inhibited very little by ciprofloxacin (Figure 3D).

\section{Effects of ciprofloxacin on diclofenac-induced enteropathy}

Diclofenac-induced enteropathy was measured following the oral administration of diclofenac (Figure 4). The results showed that rats treated with diclofenac for $6 \mathrm{~d}$ developed serious ulceration on the mesenteric side in quartiles 2, 3 and 4 of the small intestine. The diclofenac-induced enteropathy was region-dependent, and the strongest damage occurred in quartile 3 of the small intestine (Figure 5A and 5B), followed by quartile 4 and quartile 2 . The co-administration of ciprofloxacin alleviated the diclofenac-induced enteropathy, leading to a decrease in the total number and summed area of intestinal ulcers in the four quartiles by $42 \%$ and $80 \%$ of rats treated with diclofenac alone, respectively.

Diclofenac-induced enteropathy was also measured following the intravenous administration of diclofenac (Figure 6). Rats treated with an intravenous dose of diclofenac for 15 $\mathrm{d}$ showed obvious enteropathy, but the extent of the enteropathy induced by an intravenous dose of diclofenac was less than that induced by an oral dose. Co-administration of ciprofloxacin alleviated the diclofenac-induced enteropathy after intravenous administration of diclofenac, as evidenced by decreases in both the number and the total area of the intestinal ulcers (Figure 5C and 5D).

\section{Discussion}

This study clearly demonstrated that the pharmacokinetic profiles of diclofenac displayed the typical characteristics of 

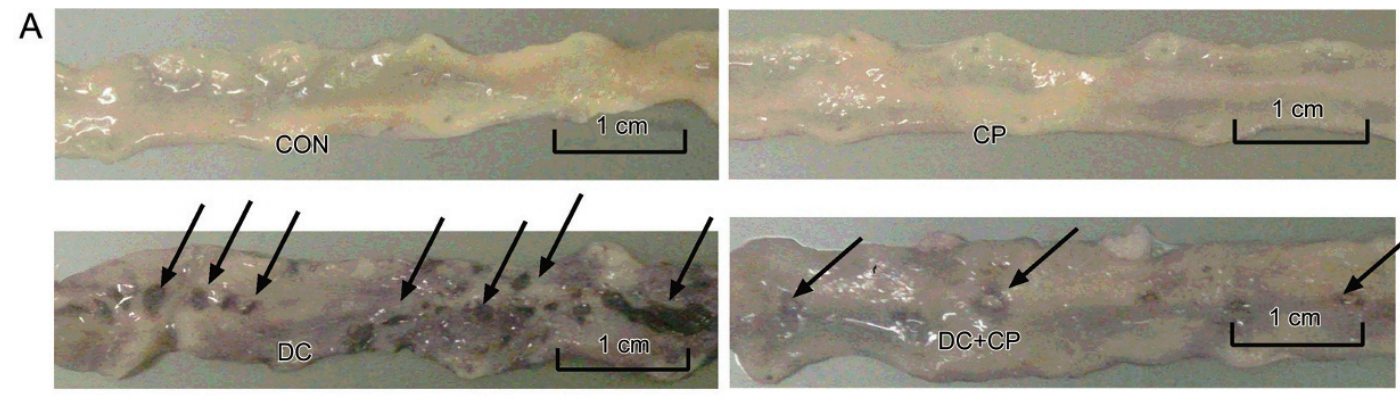

B
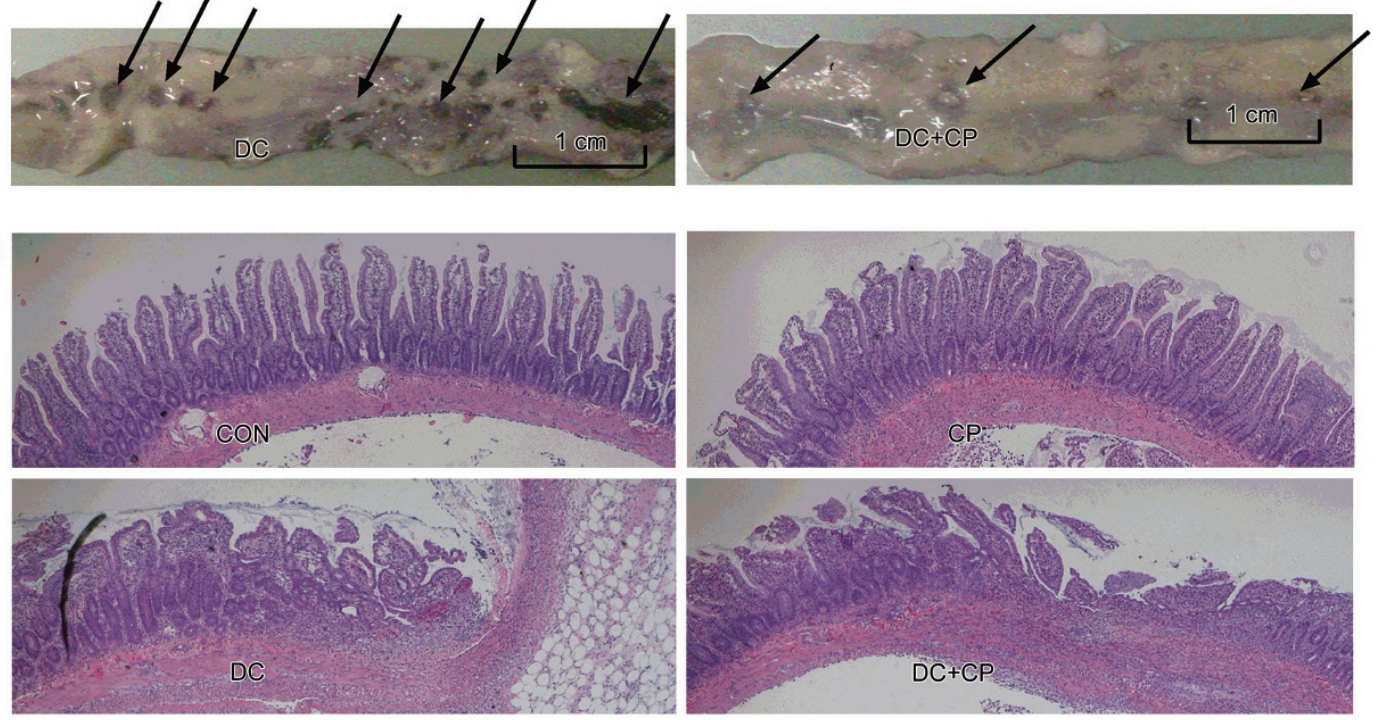

Figure 4. Macroscopic (A) and histopathologic (B) assessment of the mucosal damage in quartile 3 of the small intestine at $2 \mathrm{~h}$ following the 6 th oral dose of diclofenac alone (DC), ciprofloxacin alone (CP), diclofenac co-administered ciprofloxacin (DC+CP) and normal saline (CON). A macroscopic view of the luminal side of the small intestine was obtained following NBT staining, and a histopathologic assessment of the small intestine was performed following staining with hematoxylin and eosin ( $\times 40$ magnification). Arrows indicate typical ulcers.
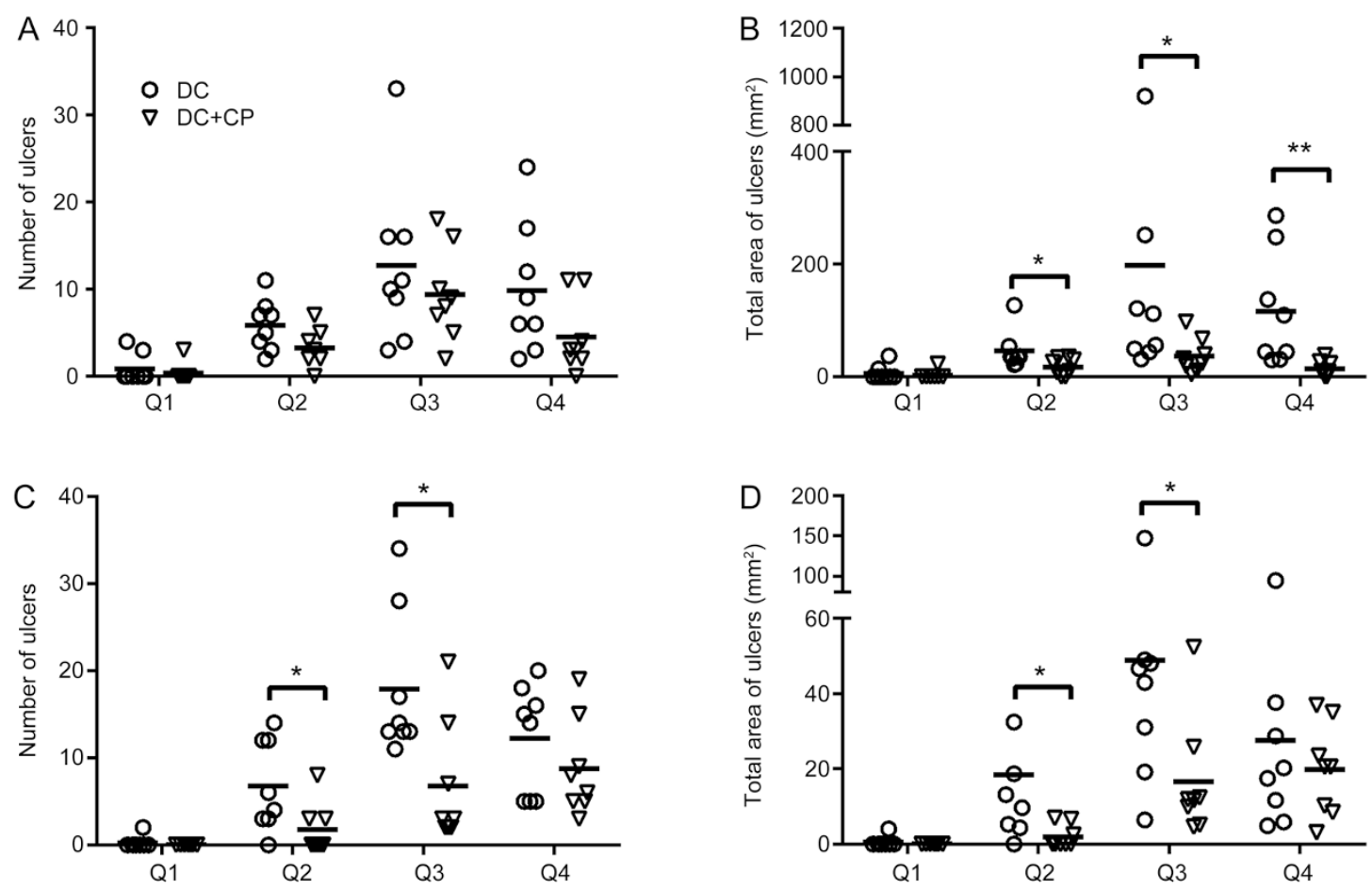

Figure 5. The effects of ciprofloxacin on diclofenac-induced enteropathy following 6 oral doses (A and B) and 15 intravenous doses (C and D) of diclofenac. The total area of ulcers and the numbers of ulcers in the small intestine quartiles of rats (Q1-Q4) were examined and calculated. The symbols represent the number of lesions or areas in individual rats, and the horizontal bars represent the means of each group; ${ }^{*} P<0.05,{ }^{* *} P<0.01$ $\mathrm{DC}+\mathrm{CP}$ rats vs $\mathrm{DC}$ rats in each quartile. 
A
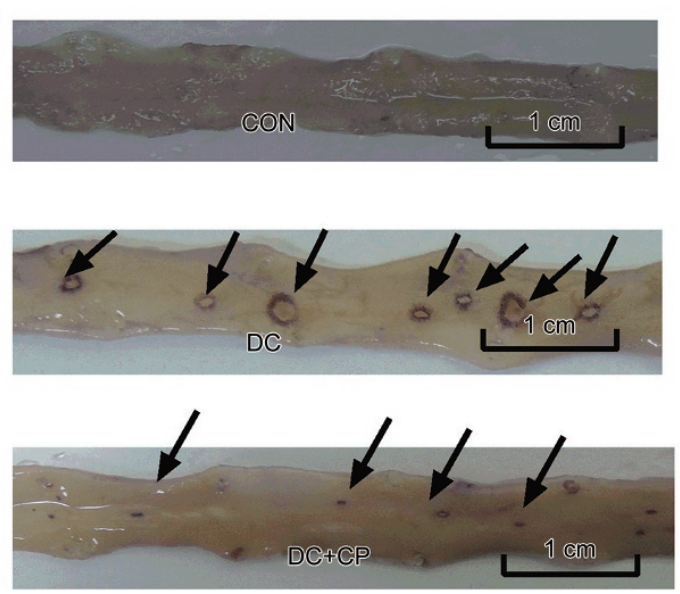

B
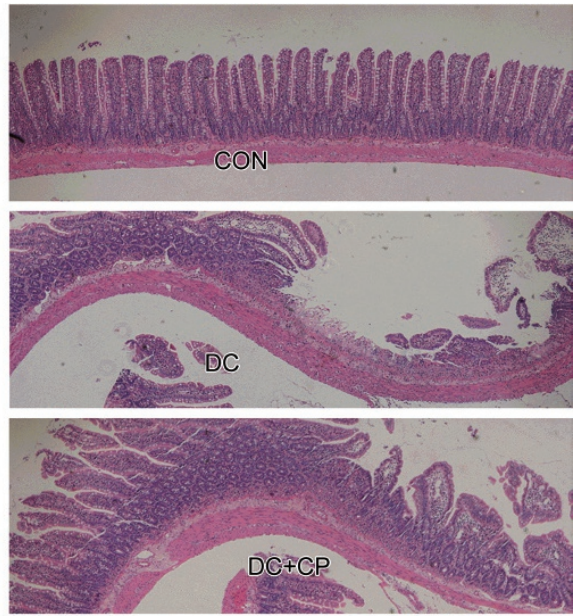

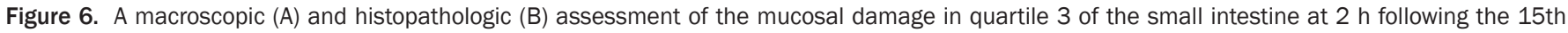

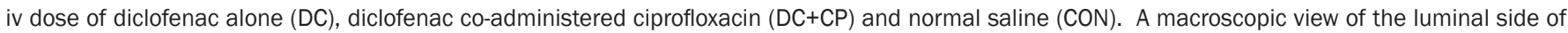

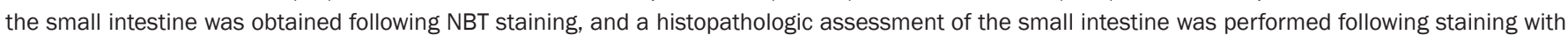
hematoxylin and eosin (×40 magnification). Arrows indicate typical ulcers.

hepatoenteric circulation following both intravenous and oral administration in rats. Co-administration of ciprofloxacin attenuated the hepatoenteric circulation. Data from the in situ intestinal perfusion and biliary excretion experiments showed that ciprofloxacin did not affect the intestinal absorption of diclofenac, or biliary excretion of diclofenac and DC-AG. A previous study showed that ciprofloxacin inhibited the hydrolysis of mycophenolic acid glucuronide to mycophenolic acid by inhibiting $\beta$-glucuronidase ${ }^{[17]}$. A recent study demonstrated an inhibitory effect of ciprofloxacin on the $\beta$-glucuronidase-mediated deconjugation of the irinotecan metabolite SN-38-G ${ }^{[33]}$. The present study also showed that the $\beta$-glucuronidase activity gradually increased along the proximal small intestine toward the ileal valve in $\mathrm{CON}$ rats. The $\beta$-glucuronidase activity of the distal small intestine and the ileal valve of rats treated with ciprofloxacin was lower than that in CON rats, consistent with finding in the small intestine of rats treated with ciprofloxacin that the in vitro incubation of ciprofloxacin remarkably inhibited diclofenac formation in the distal small intestine, without affecting DC-AG hydrolysis in the proximal small intestine. It has been generally accepted that the $\beta$-glucuronidase in the distal small intestine was predominantly secreted by microflora (mainly by $E$ coli $)^{[34]}$ and the $\beta$-glucuronidase in the proximal small intestine primarily came from the intestinal wall ${ }^{[35]}$. In the present study, the distal small intestinal tract showed a higher ratio of diclofenac to DC-AG than the proximal small intestinal tract did, which was agreement with the regional distribution of $\beta$-glucuronidase activity.

A small-molecule inhibitor of bacterial $\beta$-glucuronidase was reported to protect mice against diclofenac-induced enteropathy $^{[22,23]}$. Animal experiments also showed that antibiotic treatment efficiently alleviated NSAID-associated ulceration by inhibiting the intestinal microflora ${ }^{[36]}$. In order to investigate whether the co-administration of ciprofloxacin protected rats from diclofenac-induced enteropathy, diclofenac-induced enteropathy was assessed following the oral and intravenous administration of diclofenac. As expected, rats treated with oral and intravenous doses of diclofenac developed enteropathy in a region-dependent manner, although the enteropathy induced by the oral administration of diclofenac was more severe than that induced by the intravenous administration. Serious damage primarily occurred in the distal small intestine. Co-administration of ciprofloxacin alleviated the diclofenac-induced enteropathy, evidenced by an obvious decrease in the number and the total area of intestinal ulcers. The extent of diclofenac-induced enteropathy was also in accord with $\beta$-glucuronidase activity, implying a role for the $\beta$-glucuronidase activity in diclofenac-induced enteropathy.

Although several reports on the development of enteropathy by single dose of diclofenac in animal model exist ${ }^{[37-41]}$, the dosages of diclofenac used in these studies were much higher than the clinical dosage. The present study showed that rats orally treated with $10 \mathrm{mg} / \mathrm{kg}$ of diclofenac (equivalent to a clinical dosage of $120 \mathrm{mg}$ in a $70 \mathrm{~kg}$ human) daily for $6 \mathrm{~d}$ also developed typical enteropathy. It is well known that the microflora plays an important role in NSAID-induced enteropathy via two pathways. First, $\beta$-glucuronidase secreted by bacteria hydrolyzes NSAID glucuronides into aglycones, and the aglycones directly damage the small intestine. Second, bacteria invade the deep layers of the mucosa and harm the intestinal cells by activating Toll-like receptors ${ }^{[24]}$. The present study demonstrated an inhibitory effect of ciprofloxacin on $\beta$-glucuronidase both in vitro and in vivo. In addition, ciprofloxacin is an antibiotic active against gram-negative bacteria. All these results indicate that ciprofloxacin alleviated the diclofenac-induced enteropathy by both inhibiting DG-AG hydrolysis and killing intestinal bacteria.

In conclusion, the present study demonstrated that coadministration of ciprofloxacin attenuated the enterohe- 
patic circulation of diclofenac and alleviated diclofenacinduced enteropathy in rats, partly by inhibiting the intestinal $\beta$-glucuronidase activity. Although it may be not appropriate to use ciprofloxacin for alleviating diclofenac-induced enteropathy due to the strict control of the use of this antibiotic in the clinic, the present study may provide a clue that the inhibition of bacterial $\beta$-glucuronidases with a bacterial-specific chemical inhibitor could efficiently alleviate NSAIDs-induced enteropathy and that bacterial $\beta$-glucuronidases could be explored as a new pharmacologic target for the development of GI-protective drugs against NSAID-induced enteropathy.

\section{Acknowledgements}

The project was supported by the Priority Academic Program Development of Jiangsu Higher Education Institutions and the Policy Directive Program of Jiangsu Province (BY2015072-03).

\section{Author contribution}

Ze-yu ZHONG and Xiao-dong LIU designed and performed the research, analyzed the data, and wrote the manuscript; Bin-bin SUN, Nan SHU, Qiu-shi XIE, Xian-ge TANG, Zhao-li LING, Fan WANG, and Mian ZHANG performed the research and reviewed the manuscript; Kai-jing ZAHO, Ping XU, Ying $\mathrm{LI}$, and Yang CHEN performed the research and analyzed the data; Li LIU and Lun-zhu XIA reviewed and edited the manuscript.

\section{Abbreviations}

CON rats, normal control rat; $\mathrm{CP}$ rats, rats treated with ciprofloxacin; $\mathrm{DC}$ rats, rats treated with diclofenac; $\mathrm{DC}+\mathrm{CP}$ rats, rats treated with diclofenac and ciprofloxacin; DC-AG, diclofenac acyl- $\beta$-D-glucuronide; E coli, Escherichia coli; $P_{\text {eff }}$ apparent effective permeability; NBT, nitroblue tetrazolium.

\section{References}

1 Gan TJ. Diclofenac: an update on its mechanism of action and safety profile. Curr Med Res Opin 2010; 26: 1715-31.

2 Wallace JL. Mechanisms, prevention and clinical implications of nonsteroidal anti-inflammatory drug-enteropathy. World J Gastroenterol 2013; 19: 1861-76.

3 Bjarnason I, Hayllar J, MacPherson AJ, Russell AS. Side effects of nonsteroidal anti-inflammatory drugs on the small and large intestine in humans. Gastroenterology 1993; 104: 1832-47.

4 Granfors MT, Backman JT, Neuvonen M, Neuvonen PJ. Ciprofloxacin greatly increases concentrations and hypotensive effect of tizanidine by inhibiting its cytochrome P450 1A2-mediated presystemic metabolism. Clin Pharmacol Ther 2004; 76: 598-606.

5 McLellan RA, Drobitch RK, Monshouwer M, Renton KW. Fluoroquinolone antibiotics inhibit cytochrome P450-mediated microsomal drug metabolism in rat and human. Drug Metab Dispos 1996; 24 : 1134-8.

6 Nix DE, DeVito JM, Whitbread MA, Schentag JJ. Effect of multiple dose oral ciprofloxacin on the pharmacokinetics of theophylline and indocyanine green. J Antimicrob Chemother 1987; 19: 263-9.

7 Schwartz J, Jauregui L, Lettieri J, Bachmann K. Impact of ciprofloxacin on theophylline clearance and steady-state concentrations in serum. Antimicrob Agents Chemother 1988; 32: 75-7.

8 Mahr G, Sorgel F, Granneman GR, Kinzig M, Muth P, Patterson K, et al. Effects of temafloxacin and ciprofloxacin on the pharmacokinetics of caffeine. Clin Pharmacokinet 1992; 22: 90-7.

9 Raaska K, Neuvonen PJ. Ciprofloxacin increases serum clozapine and $\mathrm{N}$-desmethylclozapine: a study in patients with schizophrenia. Eur J Clin Pharmacol 2000; 56: 585-9.

10 Herrlin K, SegerdahI M, Gustafsson LL, Kalso E. Methadone, ciprofloxacin, and adverse drug reactions. Lancet 2000; 356: 206970.

11 Vlase L, Popa A, Neag M, Muntean D, Leucuta SE. Pharmacokinetic interaction between zolpidem and ciprofloxacin in healthy volunteers. Eur J Drug Metab Pharmacokinet 2011; 35: 83-7.

12 Erol H, Beder N, Caliskan T, Dundar M, Unsal A, Culhaci N. Can the effect of antibiotherapy and anti-inflammatory therapy on serum PSA levels discriminate between benign and malign prostatic pathologies? Urol Int 2006; 76: 20-6.

13 Huber CE, LaBerge T, Schwiesow T, Carroll K, Bernstein PS, Mamalis $\mathrm{N}$. Exophiala werneckii endophthalmitis following cartaract surgery in an immunocompetent individual. Ophthalmic Surg Lasers 2000; 31: 417-22.

14 Khan HA, Amitava AK. Topical diclofenac versus dexamethasone after strabismus surgery: a double-blind randomized clinical trial of anti-inflammatory effect and ocular hypertensive response. Indian J Ophthalmol 2007; 55: 271-5.

15 Borrows R, Chusney G, James A, Stichbury J, Van Tromp J, Cairns $\mathrm{T}$, et al. Determinants of mycophenolic acid levels after renal transplantation. Ther Drug Monit 2005; 27: 442-50.

16 Borrows R, Chusney G, Loucaidou M, James A, Van Tromp J, Cairns T, et al. The magnitude and time course of changes in mycophenolic acid 12-hour predose levels during antibiotic therapy in mycophenolate mofetil-based renal transplantation. Ther Drug Monit 2007; 29: 1226.

17 Kodawara T, Masuda S, Yano Y, Matsubara K, Nakamura T, Masada M. Inhibitory effect of ciprofloxacin on beta-glucuronidase-mediated deconjugation of mycophenolic acid glucuronide. Biopharm Drug Dispos 2014; 35: 275-83.

18 Peris-Ribera JE, Torres-Molina F, Garcia-Carbonell MC, Aristorena JC, Pla-Delfina JM. Pharmacokinetics and bioavailability of diclofenac in the rat. J Pharmacokinet Biopharm 1991; 19: 647-65.

19 Tabata K, Yamaoka K, Fukuyama T, Nakagawa T. Evaluation of intestinal absorption into the portal system in enterohepatic circulation by measuring the difference in portal-venous blood concentrations of diclofenac. Pharm Res 1995; 12: 880-3.

20 Fukuyama T, Yamaoka K, Ohata Y, Nakagawa T. A new analysis method for disposition kinetics of enterohepatic circulation of diclofenac in rats. Drug Metab Dispos 1994; 22: 479-85.

21 Tsuchiya T, Terakawa M, Ishibashi K, Noguchi H, Kato R. Disposition and enterohepatic circulation of diclofenac in dogs. Arzneimittelforschung 1980; 30: 1650-3.

22 LoGuidice A, Wallace BD, Bendel L, Redinbo MR, Boelsterli UA. Pharmacologic targeting of bacterial beta-glucuronidase alleviates nonsteroidal anti-inflammatory drug-induced enteropathy in mice. J Pharmacol Exp Ther 2012; 341: 447-54.

23 Saitta KS, Zhang C, Lee KK, Fujimoto K, Redinbo MR, Boelsterli $U A$. Bacterial beta-glucuronidase inhibition protects mice against enteropathy induced by indomethacin, ketoprofen or diclofenac: mode of action and pharmacokinetics. Xenobiotica 2014; 44: 28-35.

24 Boelsterli UA, Redinbo MR, Saitta KS. Multiple NSAID-induced hits injure the small intestine: underlying mechanisms and novel strategies. Toxicol Sci 2013; 131: 654-67.

25 al-Khamis KI, Jim LK, Bawazir SA, Ashour LF, el-Sayed N, el-Sayed YM. Effect of famotidine on ciprofloxacin pharmacokinetics after single 
intravenous and oral doses in rats. J Clin Pharm Ther 1994; 19: 335-9.

26 Huntjens DR, Strougo A, Chain A, Metcalf A, Summerfield S, Spalding DJ, et al. Population pharmacokinetic modelling of the enterohepatic recirculation of diclofenac and rofecoxib in rats. $\mathrm{Br} J$ Pharmacol 2008; 153: 1072-84.

27 Torres-Lopez JE, Lopez-Munoz FJ, Castaneda-Hernandez G, FloresMurrieta FJ, Granados-Soto V. Pharmacokinetic-pharmacodynamic modeling of the antinociceptive effect of diclofenac in the rat. J Pharmacol Exp Ther 1997; 282: 685-90.

28 Zhu M, Wong PY, Li RC. Influence of Sanguisorba officinalis, a mineral-rich plant drug, on the pharmacokinetics of ciprofloxacin in the rat. J Antimicrob Chemother 1999; 44: 125-8.

29 Jiang S, Zhao W, Chen Y, Zhong Z, Zhang M, Li F, et al. Paroxetine decreased plasma exposure of glyburide partly via inhibiting intestinal absorption in rats. Drug Metab Pharmacokinet 2015; 30: 240-6.

30 Sutton SC, Rinaldi MT, Vukovinsky KE. Comparison of the gravimetric, phenol red, and ${ }^{14} \mathrm{C}$-PEG-3350 methods to determine water absorption in the rat single-pass intestinal perfusion model. AAPS PharmSci 2001; 3: E25.

31 Li F, Wang D, Xu P, Wu J, Liu L, Liu X. Identification of the metabolites of anti-inflammatory compound clematichinenoside AR in rat intestinal microflora. Biomed Chromatogr 2013; 27: 1767-74.

32 Zhang J, Li P, Guo HF, Liu L, Liu XD. Pharmacokinetic-pharmacodynamic modeling of diclofenac in normal and Freund's complete adjuvant-induced arthritic rats. Acta Pharmacol Sin 2012; 33: 1372 8.

33 Kodawara T, Higashi T, Negoro Y, Kamitani Y, Igarashi T, Watanabe K, et al. The inhibitory effect of ciprofloxacin on the beta-glucuronidase- mediated deconjugation of the irinotecan metabolite SN-38-G. Basic Clin Pharmacol Toxicol 2016; 118: 333-7.

34 Hawksworth G, Drasar BS, Hill MJ. Intestinal bacteria and the hydrolysis of glycosidic bonds. J Med Microbiol 1971; 4: 451-9.

35 Xia B, Zhou Q, Zheng Z, Ye L, Hu M, Liu Z. A novel local recycling mechanism that enhances enteric bioavailability of flavonoids and prolongs their residence time in the gut. Mol Pharm 2012; 9: 324658.

36 Syer SD, Blackler RW, Martin R, de Palma G, Rossi L, Verdu E, et al. NSAID enteropathy and bacteria: a complicated relationship. J Gastroenterol 2015; 50: 387-93.

37 Atchison CR, West AB, Balakumaran A, Hargus SJ, PohI LR, Daiker DH, et al. Drug enterocyte adducts: possible causal factor for diclofenac enteropathy in rats. Gastroenterology 2000; 119: 1537-47.

38 LoGuidice A, Ramirez-Alcantara V, Proli A, Gavillet B, Boelsterli UA. Pharmacologic targeting or genetic deletion of mitochondrial cyclophilin D protects from NSAID-induced small intestinal ulceration in mice. Toxicol Sci 2010; 118: 276-85.

39 Ramirez-Alcantara V, LoGuidice A, Boelsterli UA. Protection from diclofenac-induced small intestinal injury by the JNK inhibitor SP600125 in a mouse model of NSAID-associated enteropathy. Am J Physiol Gastrointest Liver Physiol 2009; 297: G990-8.

40 Reuter BK, Davies NM, Wallace JL. Nonsteroidal anti-inflammatory drug enteropathy in rats: role of permeability, bacteria, and enterohepatic circulation. Gastroenterology 1997; 112: 109-17.

41 Seitz S, Boelsterli UA. Diclofenac acyl glucuronide, a major biliary metabolite, is directly involved in small intestinal injury in rats. Gastroenterology 1998; 115: 1476-82.

\section{Correction}

Correction for "Functional implications of axon initial segment cytoskeletal disruption in stroke" by Ohad STOLER, Ilya A FLEIDERVISH, which was published in Acta Pharmacol Sin (2016) 37: 75-81; doi: 10.1038/aps.2015.107.

The funding acknowledgements is as follows:

This research was supported by the Israel Science Foundation (grant № 1302/14). 